\title{
The effectiveness of intimacy training with cognitive- behavioral approach on couples' life quality and happiness
}

\author{
Hossein Pourmousa ${ }^{1}$, Mohammad Ali Mohammadifar $^{2}$, Siavash Tale Pesand ${ }^{3}$, Ali Mohammad Rezaei ${ }^{4}$
}

\begin{abstract}
Objective: Current research aimed to study the effectiveness of intimacy training on couples' quality of life and happiness.

Method: The research method was semi experimental namely: pretest-posttest and follow up with witness group. The population was Kerman couples aged 18-26, and 50 couples with consideration of entrance criterion were selected and divided randomly. Oxford happiness and quality of life questionnaire were administered among selected sample.

Results: The results showed intimacy training enhanced physical health, mental health, and social relationship of components of quality of life. Also, intimacy training enhanced life satisfaction, self-esteem, and mind satisfaction of components of happiness.

Conclusion: With consideration of results it can be said intimacy training could be used in counseling clinics.
\end{abstract}

Keywords: intimacy, life quality, happiness, training

\section{INTRODUCTION}

Marriage is one of the most important events in human life, which has been consisting of two people with talents, abilities, needs and interests. Marriage is a complex, delicate and dynamic human relationship with specific characteristics $(1,2)$ and one of the most important and highest social practices to meet human, emotional and spiritual needs (3).

The family is also the first social organization created by this marriage and has existed since the onset of human life and is considered to be the basis of life and is essentially the center of help, reassurance, tranquility and healing. It relieves the suffering of its members and directs them to growth and prosperity $(1,4)$.

One of the damages that families face today is the establishment of non-principled and problematic relationships between couples and the coldness of relationships and, ultimately, an increase in divorce rates. Intimate is the most important element of marital life, if men and women cannot accurately identify each other, they can never be integrated into one single unit and cannot be integrated together (5).

The need for intimacy and close connection with each other is one of the basic needs of each individual and is an important part of a marvelous marriage that, according to Sharer \& Reis, is the result of an interpersonal experience $(6$, $7,8)$, which its creation and preservation in marriage is a skill and art, which, in addition to mental health and healthy initial experiences, requires the acquisition of skills and performing special duties (9). Intimacy is the proximity, similarity and loving personal relationship with another that requires awareness, deep understanding, acceptance, and expression of thoughts and feelings.

Intimacy is one of the key features of communication especially among couples that affects marital adjustment and mental health (such as reducing the risk of depression, increasing happiness and well-being) and provides a satisfying life for individuals $(10,44)$. In contrast, intimacy is one of the most common causes of distress, and if people do not have the art of establishing this intimacy, the result is a conflict in the lives of individuals who, if these contradictions persist, may lead to a storm's life that even goes forward up to extinction of family foundation.

\footnotetext{
Ph.D. student in Educational Psychology, Semnan University, Semnan, Iran.

2 Assistant Professor of Psychology, Semnan University, Semnan, Iran.

3 Associate Professor of Psychology, Semnan University, Semnan, Iran

4 Assistant Professor of Psychology, Semnan University, Semnan, Iran
}

Correspondence: Mohammad Ali Mohammadifar

Assistant Professor of Psychology, Semnan University, Semnan, Iran.

E-mail: alimohammadyfar@semnan.ac.ir

Received: 26 Mar 2018, Accepted: 14 May 2018

(C) 2018 by the authors; licensee Modestum Ltd., UK. This article is an open access article distributed under the terms and conditions of the Creative Commons Attribution License (http://creativecommons.org/licenses/by/4.0/). 
According to the statistics office of Iran, during the last decade, the number of registered divorces has increased and has progressed over the past years $(10,11)$, This, in turn, can dominate the quality of life, welfare and happiness, and generally the individual's satisfaction from life, but the important thing is that not only intimacy and communication skills can be addressed to individuals. It can prevent this phenomenon, but it even increases the factors such as the quality of life and happiness that are important psychological factors in the lives of each individual $(6,12,13)$.

The quality of life is defined as a cognitive judgment of life satisfaction. The World Health Organization has defined the quality of life as perceiving individuals from their present conditions according to their culture and their value system relationship with their goals, expectations, standards and concerns and their effects on physical and psychosocial conditions (14). Studies on quality of life have shown that quality of life is related to marital intimacy $(15,16)$.

Barzegar and Samani (17) and the training of the communication skills program $(18,19,20,21,22,23)$; and training on the program for the enrichment of relations $(24,25,26)$ on quality of life which has had an effect on the quality of life of individuals and has led to an improvement in the quality of life of individuals.

Happiness means being happy and having a positive attitude in life and one of the most important psychological needs of a person, which also has a significant effect on the quality of human life. Happiness is recognized by the satisfaction of high life, positive emotions and low levels of negative emotions (Morrow-Howell, 2010; quoted by Meyzari Ali and the Dasht bozorgi, 2015). Happiness studies have shown that there is a relationship between communication skills and couples happiness (27), and couples whose happiness levels were higher in them were being reported high intimacy (28) they also suggested that the training of communicational skills program (29) is effective in increasing happiness.

Therefore, considering that marriage is one of the most important stages in the life of each person, paying attention to the psychological issues of couples for the creation of a family and the subsequent healthy community is necessary, and this is dependent on the use of the couple's skills and abilities in this field, as well as Taking into account the existing gap between researches that have not been conducted solely in the field of in-service training, The main question of the present research is that: Does intimacy education affect the quality of life and the happiness of couples?

\section{SOCIETY, SAMPLE AND SAMPLING METHOD}

The methodology of the research is a quasi-experimental research from pre-test, post-test, and control group. The statistical population of this study consisted of married couples aged 20 to 27 years old in Kerman, in order to select the sample of about 3,000 couples who were introduced to undergraduate training centers for premarital training (of which $65 \%$ were in the desired age range), 50 couples were selected by random sampling method according to the criteria for entering the research and were randomly assigned to the experimental and control groups. The criteria for entry were: age range of 20 to 27 years old, having at least a diploma, no serious physical or mental illness. Exit criteria were: an unpleasant experience in the last few months (such as the death of a dear), the history of divorce / remarriage.

\section{TOOLS}

1. Quality of Life Questionnaire: This questionnaire is used to measure the quality of life of a person in the last two weeks and has been developed by the WHO in 1989. This questionnaire has 26 items and 4 areas of physical $\{3,4,10$, $15,16,17,18\}$, social relationships $\{20,21,22\}$, environmental health $\{8,9,12,13,14,23,24,25\}$ can be psychological $\{5$, $6,7,11,19,26\}$. The first two questions of this questionnaire do not fall into any of these subscales and are not in this range (30).

The spectrum of this questionnaire is Likert type and ranks from 1 to 5 from the completely disagree to the completely agree. Nassiri (31) reported the reliability of this scale based on three retest methods with a three-week distance, halflife and Cronbach's alpha of 0.67, 0.87 and 0.84, respectively. Rahimi and Kheir (32) reported the Cronbach's alpha coefficient for the physical health dimension equal to 0.77 , the psychological health dimension equal to 0.77 , the dimension of the social relationship equal to 0.65 and the dimension of life environment have been reported equal to 0.77 .

2. Oxford Happiness questionnaire: This scale has been developed by Argyll and Lev in 1989. This questionnaire has 29 items. The scale of the questionnaire is Likert type and ranked 0 to 3 . The original version of this questionnaire has not sub-scale but the results of Hadinejad and Zarei's research (33) have suggested seven factors in this questionnaire: self-concept \{items of $1,6,10,13,14,19,23,24\}$, life satisfaction \{items of $3,9,12\}$, psychological readiness \{items of 18 , 
Table 1: Summary of intimacy training sessions based on cognitive-behavioral approach

Session Contents of the sessions

First Communicating and making readiness (communicating and familiarizing with couples' communication status, including factors of cognitive, communication, behavioral, and conflict resolution methods, conceptualization, familiarization of couples).

Second Cognitive factors (identifying couples' beliefs and expectations about intimacy and marital relationships, showing the effect of beliefs on

fecondings and behaviors). Assignment: Completing the cognitive table.

Cognitive factors (studying how to take and explain the behavior of a spouse, correcting cognitive errors and replacing rational beliefs,

Third resolving misunderstandings due to misconceptions or different perceptions and replacing rational beliefs and expectations, explaining cognitive errors, explaining the goals and realistic expectations of familiarity With mutual expectations and attention to the positive characteristics of each other). Assignment: re-completion of the cognitive table and the column of substitute thoughts.

Cognitive Factors (Determine the realist goals and expectations about self, spouse and intimate relationships, creation of the skill of

Fourth transmitting and clear receiving, correct and effective thoughts, feelings and needs of each other. Evaluation of the problems of the sender and receiver of the message, training and educating the sender's skills and message receiver). Assignment: Practicing what the wife likes.

Communication skills (assessing the message and transmitter bugs, creating skills for transferring and receiving clear and effective

Fifth thoughts, emotions and needs, creating empathic understanding and listening skills, evaluating couples' patterns and barriers, practicing and teaching effective communication skills). Assignment: Practice the skills and instructions of the sender and receiver of the message.

Sixth Communication skills (training and effective communication skills training). Assignment: Practicing verbal and non-verbal communication. Behavioral skills (Understanding patterns of spousal reinforcement and punishment, increasing positive behavioral exchanges and

Seventh decreasing punishment, recognizing patterns of empowerment and punishment of each spouse, increasing positive reinforcements and reducing punishment). Assignment: Couples practice at least two positive behaviors and a negative behavior reduction.

Problem solving skills (problem solving skills training, Doing a problem solving method for one of the problems of couples, Reduce

Eighth Problems and Learn Problem Solving Skills, Examining the existing problems and evaluating spouse problem solving methods, Teaching and practicing the steps of the problem solving method, Reducing conflicts between spouses, Study of conflicts between spouses, Investigating Conflict Resolution Patterns and Its Outcomes, Training and practice conflict resolution methods).

Ninth Conflict Resolution Skills (Studying Conflicts and Conflict Resolution of the Couples). Assignment: Compilation of conflicts and practice Ninth solving conflicts.

Tenth Evaluation and conclusion (evaluation of couples' change and improvement of intimate relationships)

$20,21,25\}$, being alert $\{\mid$ tems 11,15$\}$, aesthetic sensation \{ltems of $2,4,7,16,27\}$, self-efficacy \{items of $8,17,22,26\}$ and hopefulness \{items 28, 29\}.

The results of the study by Ali Pour and Agah Harris (34), indicate that there are five factors in this questionnaire: life satisfaction \{items 1, 2, 3, 5, 6, 8, 24, 26\}, self-esteem \{ltems of 4, 10,11, 13, 14, 15, 20,21, 23\}, Subjective well-being \{items of $12,16,18,19,29\}$, satisfaction $\{$ Items of 7, 9, 17, 23, 25\} and positive creations \{ltems of 22, 27, 28\}. Ali Pour and Agah Harris (34) have reported the Cronbach's alpha coefficient for this scale of 0.91.

Mozafarynia et al. (35), Cronbach's alpha coefficient equal to 0.94, Hadinejad and Zarei (33), Cronbach's alpha coefficient equal to 0.84 , and the coefficient of retest equal to 0.78 , Alipour and Noorbala (1998), Cronbach's alpha coefficient equal to 0.93 , The two-half test reliability coefficient 0.92 and the reliability of the retest have been reported equal to 0.79 for this questionnaire. A questionnaire with the sub-scales of Ali Pour and Agah Harris has been used in this research.

\section{IMPLEMENTATION METHOD}

At first, 50 couples were selected according to the criteria for entering the research and available sampling method. In the next step, the subjects were randomly assigned to experimental and control groups and pre-test was performed on them. Then, the experimental group was trained for 10 sessions, 45 minutes under intimacy training with cognitivebehavioral approach, but no training was performed for the control group. In this research, intimacy training sessions were conducted based on the guidelines of Etemadi, Rezaei and Ahmadi (36). The post-test was taken after the end of the treatment plan. A summary of what was raised at the treatment sessions has been presented in Table $\mathbf{1}$.

\section{FINDINGS}

The descriptive statistics of happiness components by groups and type of test have been presented in Table 2 . 
Table 2: Descriptive statistics of the components of happiness by groups and type of test

\begin{tabular}{|c|c|c|c|c|c|}
\hline Variables & Groups & Test type & Mean & Sd & Number \\
\hline \multirow{4}{*}{ Life satisfaction } & \multirow{2}{*}{ Control } & Pre-test & 16.27 & 3.55 & 26 \\
\hline & & Post-test & 16.38 & 3.34 & 26 \\
\hline & \multirow{2}{*}{ Intimacy training } & Pre-test & 15.15 & 4.84 & 26 \\
\hline & & Post-test & 17.23 & 3.82 & 26 \\
\hline \multirow{4}{*}{ Self-esteem } & \multirow{2}{*}{ Control } & Pre-test & 16.88 & 2.89 & 26 \\
\hline & & Post-test & 16.77 & 3.00 & 26 \\
\hline & \multirow{2}{*}{ Intimacy training } & Pre-test & 16.61 & 2.32 & 26 \\
\hline & & Post-test & 18.81 & 3.03 & 26 \\
\hline \multirow{8}{*}{ Well-being } & \multirow{2}{*}{ Control } & Pre-test & 11.04 & 2.22 & 26 \\
\hline & & Post-test & 11.31 & 2.24 & 26 \\
\hline & \multirow{2}{*}{ Intimacy training } & Pre-test & 11.11 & 2.66 & 26 \\
\hline & & Post-test & 11.23 & 2.37 & 26 \\
\hline & \multirow{2}{*}{ Control } & Pre-test & 9.77 & 1.88 & 26 \\
\hline & & Post-test & 9.96 & 1.87 & 26 \\
\hline & \multirow{2}{*}{ Intimacy training } & Pre-test & 9.54 & 2.40 & 26 \\
\hline & & Post-test & 10.46 & 2.19 & 26 \\
\hline \multirow{4}{*}{ Satisfaction } & \multirow{2}{*}{ Control } & Pre-test & 6.04 & 1.78 & 26 \\
\hline & & Post-test & 6.42 & 1.79 & 26 \\
\hline & \multirow{2}{*}{ Intimacy training } & Pre-test & 6.11 & 1.63 & 26 \\
\hline & & Post-test & 6.19 & 1.88 & 26 \\
\hline
\end{tabular}

Table 3: Leven test results for evaluating the variances of error

\begin{tabular}{lccc}
\hline Variables & Degrees of freedom & F statistics & Significant value \\
\hline Life satisfaction & 50 & 0.238 & 0.627 \\
\hline Self-esteem & 50 & 0.044 & 0.835 \\
\hline Well-being & 50 & 0.079 & 0.78 \\
\hline Satisfaction & 50 & 2.716 & 0.106 \\
\hline Positive mood & 50 & 0.042 & 0.838 \\
\hline
\end{tabular}

Table 4: Single-variable covariance analysis results to evaluate patterns of difference in happiness components

\begin{tabular}{lcccccc}
\hline Variables & Sum of squares & Degrees of freedom & Mean Square & F statistics & Significant value & Effect size \\
\hline Life satisfaction & 34.18 & 1 & 34.18 & 6.883 & 0.012 & 0.13 \\
\hline Self-esteem & 68.60 & 1 & 68.60 & 13.445 & 0.001 & 0.23 \\
\hline Well-being & 0.69 & 1 & 0.69 & 0.993 & 0.324 & - \\
\hline Satisfaction & 10.082 & 1 & 10.089 & 4.750 & 0.035 & 0.09 \\
\hline Positive mood & 1.20 & 1 & 1.20 & 0.912 & 0.345 & - \\
\hline
\end{tabular}

Multivariate covariance analysis should be used to examine the effectiveness of intimacy training on happiness. The covariance matrix is one of the assumptions of this analysis. The results of the box test showed that this hypothesis was established ( $\mathrm{BOX} M=46.96, \mathrm{~F}=1.414, \mathrm{P}>0.05$ ). Another assumption of this analysis is the homogeneous of error variances. The results of the Leven test have been presented in Table 3.

As shown in Table 3, in all components, the condition for equality of error variances is established $(P>0.05)$. Therefore, multivariate analysis of covariance was performed and the results showed a significant difference between the two groups in the linear composition of the variables (Effect size, 0.335, P <0.01, F=4.134, Lambdia Wilkes=0.665). Onedimensional covariance analysis was used to evaluate the patterns of difference in Table 4.

As shown in Table 4, intimacy education has been affected the improving life satisfaction, self-esteem and satisfaction.

The descriptive statistics of quality of life components by groups and type of test have been presented in Table $\mathbf{5}$. 
Table 5: Descriptive statistics of quality of life components by groups and type of test

\begin{tabular}{|c|c|c|c|c|c|}
\hline Variables & Groups & Test type & Mean & Sd & Number \\
\hline \multirow{4}{*}{ Physical health } & \multirow{2}{*}{ Control } & Pretest & 55.28 & 19.70 & 26 \\
\hline & & Post-test & 55.28 & 19.71 & 26 \\
\hline & \multirow{2}{*}{ Intimacy training } & Pretest & 53.10 & 19.77 & 26 \\
\hline & & Post-test & 64.18 & 19.52 & 26 \\
\hline \multirow{4}{*}{ Psychological health } & \multirow{2}{*}{ Control } & Pretest & 52.56 & 21.44 & 26 \\
\hline & & Post-test & 52.74 & 21.31 & 26 \\
\hline & \multirow{2}{*}{ Intimacy training } & Pretest & 50.96 & 17.77 & 26 \\
\hline & & Post-test & 62.98 & 19.12 & 26 \\
\hline \multirow{4}{*}{ Social relationships } & \multirow{2}{*}{ Control } & Pretest & 57.77 & 20.99 & 26 \\
\hline & & Post-test & 56.15 & 21.12 & 26 \\
\hline & \multirow{2}{*}{ Intimacy training } & Pretest & 57.37 & 25.42 & 26 \\
\hline & & Post-test & 67.63 & 23.73 & 26 \\
\hline \multirow{4}{*}{ Environmental health } & \multirow{2}{*}{ Control } & Pretest & 55.37 & 21.68 & 26 \\
\hline & & Post-test & 56.75 & 20.94 & 26 \\
\hline & \multirow{2}{*}{$\begin{array}{l}\text { Intimacy training } \\
\text { Control }\end{array}$} & Pretest & 56.79 & 18.92 & 26 \\
\hline & & Post-test & 58.08 & 20.69 & 26 \\
\hline
\end{tabular}

Table 6: Leven test results for evaluating the variances of error

\begin{tabular}{lccc}
\hline Variables & Degrees of freedom & F statistics & Significant value \\
\hline Physical health & 50 & 0.077 & 0.782 \\
\hline Psychological health & 50 & 1.684 & 0.200 \\
\hline Social relationships & 50 & 0.511 & 0.478 \\
\hline Environmental health & 50 & 0.014 & 0.907
\end{tabular}

Table 7: Univariate covariance analysis results to evaluate patterns of difference in quality of life components

\begin{tabular}{lcccccc}
\hline Variables & Sum of squares & Degrees of freedom & Mean Square & F statistics & Significant value & Effect size \\
\hline Physical health & 1128.29 & 1 & 1128.29 & 8.483 & 0.006 & 0.156 \\
\hline mental health & 1317.28 & 1 & 1317.28 & 10.404 & 0.002 & 0.184 \\
\hline Social relationships & 1284.44 & 1 & 1284.44 & 7.685 & 0.008 & 0.143 \\
\hline Environmental health & 2.17 & 1 & 2.17 & 0.083 & 0.776 & - \\
\hline
\end{tabular}

Multivariate covariance analysis should be used to evaluate the effectiveness of intimacy training on happiness. The covariance matrix is one of the assumptions of this analysis. The results of the test showed that this hypothesis was established (Box $M=10.775, F=0.984, P>0.05$ ). Another assumption of this analysis is homogeneous of the error variances. The results of the Leven test have been presented in Table 6 .

As shown in Table 7, in all components, the condition for equality of error variances is established $(P>0.05)$. Therefore, multivariate analysis of covariance was performed and the result showed a significant difference between the two groups in the linear composition of the variables (Effect size $=0.197, \mathrm{P}<0.05, \mathrm{~F}=2.645$, Lambdia Wilkes $=0.803$ ). Univariate covariance analysis was used to evaluate the patterns of difference, in Table 7.

As shown in Table 7, intimacy training has been affected the improving physical health, mental health, and social relationships.

\section{DISCUSSION AND CONCLUSION}

The purpose of this study was to investigate the effect of Intimacy training on couples' quality of life and happiness. The results showed that intimacy education has been effective on the quality of life and happiness of couples, and it promotes quality of life and happiness. This finding is implicitly based on the findings of Reza Zadeh Goli and Kiani (15); Farshid Mansesh et al. (16); Barzegar and Samani (17); Sarmeddi Sultan et al. (18); Fuladi et al. (19); Kargar et al. (20); Farbod et al. (21); Fathi Aqdam et al. (22); Fukuyei et al. (23); Amini and Heidari (24); Amini and Kaboli (25); Sabzevari and Gerami (26).

The researchers concluded that quality of life has been linked to marital intimacy, and the training of communicative skills and education and programs on the enhancement of relationships on quality of life had an effect on the quality of life of individuals. The findings of this study are also consistent with Klein and Stafford (27), Sanhedia (28), Shayan and Ahmadi Gattat (29). 
These researchers concluded that there is a relationship between couples' communication skills and happiness, and couples with higher levels of happiness were being reported higher intimacy and also that communication skills training is effective on increasing happiness. Given that similar researches has not been done in the field of research, this problem has encountered difficulties in finding direct records and it cannot certainly possible to compare the findings of this study with other studies.

In explaining these findings in general, it can be said that communication problems and the inability of couples to communicate properly and correctly are the most important factors in conflict and as a result of dissatisfaction and inconsistency and the decline of quality of life. Obviously, the equipping and awareness of couples with proper and correct communication skills can lead to greater satisfaction and compatibility of marital life (37). People in this program learn the skills that change their behavior and their husbands and eventually find the ability to create new lifestyles. With the help of these skills, people can send their messages more explicitly, and they can find a deeper understanding of each other. Since couples create this style by agreement, they learn over time to change their bad behavior and communication styles, add positive behaviors to their behavioral styles, and use these habits at conflict situations and improve their quality of life.

The skills taught in this program, such as problem-solving, are biased and fairly capable of maintaining a careful atmosphere during the discussion and problem-solving, the ability to adopt an individual's perspective, the ability to reduce negative-negative interaction, and anger and ability to change in the expected behavior patterns of the individual. The empathy skills ready individuals for more compassionate understanding of the needs of the partner in terms of emotional needs, psychology and interpersonal needs, the tendencies of others, and the calling of honest, respectful and trustworthy behaviors, common sense, and sensory and supervisory behaviors and intimacy with others with more speed and amount.

The skill of negotiating couples is taught to maintain a positive emotional atmosphere so that when discussing controversial issues using these skills, they prevent the increase in anger using teaching this skill; people replace positive emotions with negative emotions. It makes people interact without anger. As a result, it can be said that the learned skills will greatly affect the improvement of quality of life and the sense of satisfaction with life $(24,21,22,38)$.

Regarding the effect of the intimacy training program on happiness, it can also be said that this skill tries to educate people who first recognize and accept themselves and then listen to their husbands, talk to them, accept the spouse, and act to resolve their conflicts. The admission of the spouse makes it easy and friendly to connect (39). Teaching communication and intimacy skills consider joint decision as the fundamental principle for marital life, and has turned the hard and inflexible rules to flexible rules and thus it leads to increase in satisfaction;

In addition, by improving couples' skills in conflict resolution, they increase positive emotions and feelings of satisfaction in couples, which in turn can increase quality of life. Communication skills create an emotional bond between couples, and the training of these skills makes people with realistic expectations, cognitive imbalance, right thinking, courage and expression that together lead to good relationships, happiness and welfare. Intimacy training teaches the principles of effective dialogue, including careful listening to the spouse and avoiding immediate response to him/her, and ... can reduce the emotional reactions of the spouses and help them to listen to each other and talk to each other effectively and usefully.

The program also provides couples with opportunities to practice new skills and receive feedback. Additionally, in this method, with regard to assignments for subsequent sessions, they are forced to practice their skills in relation to themselves, as well as these assignments will bring the couples closer together and increases the duration of to be coupled together and this factor can increase the intimacy between them and cause happiness and welfare $(20,40,41)$.

A person who experiences higher levels of intimacy in relationships can offer himself/herself in a more desirable way and express his/her needs more effectively to his/her spouse and partner. The couples will discover new and innovative ways by learning the skills in the program, that they can feel more refreshed and more satisfying with their application. These tutorials will help couples transfer their messages more accurately, more effectively, and more efficiently, as well as it leads to exchanging positive and pleasant behaviors and reducing negative behaviors;

On the other hand, the increase of positive behavioral exchanges also satisfies the emotional needs of couples, which ultimately leads to a positive feeling towards each other and happiness $(22,42,43)$.

In general, it can be said that the purpose of the intimacy training program of couples is to increase self-awareness and also to develop the ability to strengthen and maintain a happy and enjoyable relationship between husband and wife. Also this program teaches the skills that make participants take deep step in the program to self-exploration. 
The results of this study clearly illustrate that cognitive therapy sessions related to intimacy are useful and applicable in raising happiness and improving the quality of life of couples. This study showed that efficiency and effectiveness in improving the physical, psychological and environmental health of couples, as well as their social relationships are positive steps in this regard.

Due to the simple and practical application of this theory for education and treatment, which is relatively similar to our culture, it can be used to reduce problems, increase marital satisfaction, pre and post-marital education is used by psychologists (in order to prevent, enrich and strengthen the family institution). Therefore, it is suggested that social counselors and social workers focus on the strength of the family foundation to holding the classes of intimacy training for couples.

\section{REFERENCES}

1. Sharif $F$, Soleimani $S$, Mani A, Keshavarzi S. The effect of conflict resolution training on marital satisfaction in couples referring to counseling centers in Shiraz, southern Iran. International journal of community based nursing and midwifery. 2013;1(1):26-34.

2. Soltani A, Molazadeh J, Mahmoodi M, Hosseini S. A study on the effectiveness of emotional focused couple therapy on intimacy of couples. Procedia- social and behavioral sciences. 2013;82:461-465. https://doi.org/10.1016/j.sbspro.2013.06.293

3. Mohammadi A, Sohrabi R, Adalatzadeh G. Effect of narrative therapy on enhancing of couples intimacy. Procediasocial and behavioral sciences. 2013;84:1770-1772. https://doi.org/10.1016/j.sbspro.2013.07.029

4. Mehrazad saber $M$, Akbari B. Relationship between perfectionism and marital disenchantment in couples with marital conflicts. Journal of applied environmental and biological sciences. 2015;5(4):146-149.

5. Abbasi A, Jalilpour N, Kamkar A, Zadeh Bagheri G, Mohamed F. Determining the effect of life skills training on marital satisfaction of women working in Douganbadan. Armaghan Danesh. 2011;16(6):594-587.

6. Naderi F, Azammanesh P. Comparison of marital disturbance, family function and intimacy of male and female employees. New findings in psychology. 2012;7(22):112-97.

7. Kim M. The effect of marital intimacy, Sex communication and sexual satisfaction on the marital satisfaction for Korean middle-aged women. Journal of next generation information technology. 2013;4(8):441-448.

8. Laurenceau JP, Feldman barrett L, Rovine MJ. The interpersonal process model of intimacy in marriage: a dailydiary and multi-level modeling approach. Journal of family psychology. 2005;19(2):314-323. https://doi.org/10.1037/0893-3200.19.2.314

9. Etemadi O, Amin Ja'fari B, Shah Siyah M. The effect of couples group training on the basis of therapeutic communication approach on increasing intimacy of control and saffron couples in Isfahan. Islamic Women's Research and Family Research. 2014;2(2):38-13.

10. Kardan-Souraki M, Hamzehgardeshi Z, Asadpour I, Mohammadpour RA, Khani S. A Review of Marital IntimacyEnhancing Interventions among Married Individuals. Global journal of health science. 2016;8(8):74-93. https://doi.org/10.5539/gjhs.v8n8p74

11. Statistical Center of Iran. Iran statistical yearbook. Access Year 2015. Available at: http://www.amar.org.ir/

12. Hamid N, Roshani K. Effectiveness of interpersonal psychotherapy on decreasing the burnout of women on the verge of divorce in Ahvaz. Journal of life science and biomedicine. 2014;4(3):183-187.

13. Tizdast T, Salehi $S$, Athari M. Comparison of communication skills training and problem-solving on marital disenchantment and life quality in women with marital disputes. Arabian journal of business and management review. 2013;1(7):37-45. https://doi.org/10.12816/0003661

14. Taghipour K, Bakhshipour B, Hassan zadeh R. Relation between mental health and quality of life in heads of household women supported by welfare organization, sari, Iran. Journal of social issues \& humanities. 2013;1(7):183-186.

15. Reza Zadeh Goli Z, Kiani Q. Relationship of Marital Engagement and Quality of Life with Marital Intimacy of Married Employees of Parsian Electronic Commerce Co. Tehran. International Conference on Innovation and Research in the Humanities and Social-Cultural Studies. 2016.

16. Farshidmanesh F, Ghaderi Z, Khodadadi Z. Relationship between Family Performance and Marital Intimacy with Quality of Life in Isfahan Cancer Women. First National Conference on Educational Sciences and Psychology. 2014. 
17. Barzegar I, Samani S. The role of intermediary intimacy in the relationship between communication patterns and quality of life in marriage. Second International Conference on Psychology, Education and Lifestyle. 2015.

18. Sarmadi Soltani V, Ezzati Rastegar M, Gholamali Lavasani M. The Effectiveness of Communication Skills Training on Intimacy and Quality of Marital Life of Veterans Wives. First International Conference on Psychology and Educational Sciences. 2015.

19. Fuladi F, Ejee J, Gholamali Lavasani M, Bazgar Kavnooyi S, Faryani R. Effectiveness of communication skills training on improving the quality of life of married women. Quarterly Journal of Education and Evaluation. 2013;6(21):141-127.

20. Karegar M, Ghassed F, Kimayee A. The Effectiveness of Marital Communication Skills Training on Quality of Life and Marital Satisfaction. Journal of Cultural Education of Women and Family. 2016;11(36):141-123.

21. Farbod E, Ghamari M, Majd MA. Investigating the effect of communication skills training for married women on couples' intimacy and quality of life. SAGE Open. 2014;4(2):1-4. https://doi.org/10.1177/2158244014537085

22. Fathi Aghdam Gh, Ahadi H, Jamehri F. A Comparison of the Effectiveness of Communication Skills Training for Marital Conflicts and Quality of Life in Female Students of Islamic Azad University, Science and Research Branch. Annals of Biological Research. 2012;3(4):1994-2000.

23. Fukui S, Ogawa K, Yamagishi A. Effectiveness of communication skills training of nurses on the quality of life and satisfaction with healthcare professionals among newly diagnosed cancer patients: A preliminary study. PsychoOncology. 2011;20(12):1285-1291. https://doi.org/10.1002/pon.1840

24. Amini $M$, Heidari $H$. Evaluating the Effectiveness of Enrichment Education on Improving Quality of Life and Marital Satisfaction among Married Students. Journal of Education and Community Health. 2016;3(2):31-23.

25. Amini N, Kaboli A. The Effectiveness of Marriage Enrichment Education on Marital Intimacy and Quality of Life of Married Workers in Bushehr. The 2nd Scientific-Research Congress on the Development and Promotion of Educational Sciences and Psychology, Sociology and Social Sciences of Iran. 2015.

26. Sabzevari $\mathrm{P}$, Gramie MH. Effectiveness of education enrichment marital relations based on the model olson in quality of life. IIOAB Journal. 2016;7(4):535-538.

27. Kline SL, Stafford L. A comprised of interaction rules and interaction frequency in relationship to marital quality. Communication report. 2004;17:11-26. https://doi.org/10.1080/08934210409389370

28. Sandhya S. The social context of marital happiness in urban Indian couples: Interplay of intimacy and conflict. Journal of Marital and Family Therapy. 2009;35(1):74-96. https://doi.org/10.1111/j.1752-0606.2008.00103.x

29. Shayan N, Ahmadi Gatab T. The effectiveness of social skills training on students' levels of happiness. ProcediaSocial and Behavioral Sciences. 2012;46:2693-2696. https://doi.org/10.1016/j.sbspro.2012.05.548

30. Nejat S, Montazeri A, Halakouei Naeini C, Mohammad K, Majdzadeh R. Standardization of the WHO Quality of Life Questionnaire (WHOQOL-BREF): Translation and Psychometrics of the Iranian Species. Journal of School of Public Health and Institute of Public Health Research. 2006;4(4):12-1.

31. Nasiri $\mathrm{H}$. The validity and reliability of the World Health Organization Quality Score and its Iranian version. Third Seminar on Mental Health of Students, Tehran: University of Science and Technology. 2016.

32. Rahimi M, Kheer M. Relationship between Family Communication Patterns and Quality of Life in High School Students in Shiraz. Physical Education and Psychology Studies, Ferdowsi University. 2009;10(1):25-5.

33. Hadi Nejad H, Zarei F. Reliability, validity and standardization of the Oxford Happiness Inventory. Psychological Research. 2009;12(1-2):77-62.

34. Alipour A, Noorbala AA. Validity and Validity of Oxford Happiness List in students of University. Quarterly Journal of Solicitude and Behavior. 1998;5(1,2):56-64.

35. Mozafarinia F, Amin Shokrui F, Haydar Nia A. The Relationship between Spiritual Health and Happiness of Students. Quarterly Journal of Health Education and Promotion. 1393;2(2):107-97.

36. Etemadi O, Rezaei J, Ahmadi A. Intimacy and its role in marital life (concepts, theories, and strategies). Esfahan: Jahad University Press. 2014.

37. Mohammadi M, Salimi A, Zahrakar K, Davornia R, Shakrami M. Effectiveness of the relationship enrichment program on reduction of marital boredom of couples. Psychiatric Nursing Journal. 2016;4(3):15-8.

38. Tavakolizadeh J, Nejatian M, Soori A. The Effectiveness of communication skills training on marital conflicts and its different aspects in women. Procedia-Social and Behavioral Sciences. 2015;171:214-221. https://doi.org/10.1016/j.sbspro.2015.01.112 
39. Okwun CK. Effects of cognitive restructuring and communication skills training on conflict resolution among Nigerian couples. International Journal of Peace and Development Studies. 2011;2(6):179-189.

40. Khojasteh Mehr R, Ahmadi Ghazloujeh A, Ghoozlucheh M, Shiralinia K. Effectiveness of short-term marital counseling on the emotional intimacy and marital quality of couples. Contemporary Psychology. 2015;10(2):4029.

41. Nadimi M. Relationship between Communication Skills and Deterministic Thinking with Marital Satisfaction. Biological Forum - An International Journal. 2015;7(2):33-39.

42. Javadi BS, Afrouz G, Hosseinian S, Gholamali Lavasani M. Communication skills training and emotional interactions in the context of religious values and their effectiveness on the emotional interactions of couples in the family. The 5th Islamic Model of Islamic Development Conference; Progress Basic Model. 2016.

43. Naghdi Babaee S, Ghahari S. Effectiveness of communication skills training on intimacy and marital adjustment among married women. Health Sciences. 2016;5(8):375-380.

44. Bagarozzi A, Dennis A. Enhancing intimacy in marriage. Branner- Rouledy. Taylor \& Francis group: USA. 2001.

45. Meyzari Ali R, Dasht Bozorgi Z. The Relationship of Altruistic Behavior, Empathetic Sense, and Social Responsibility with Happiness among University Students. Practice in Clinical Psychology. 2016;4(1):51-56.

$\diamond \diamond \diamond \diamond \diamond \diamond \diamond$

http://www.ejgm.co.uk 